\title{
MAXIMUM ENTROPY MODELING (MAXENT) OF CURRENT AND FUTURE DISTRIBUTIONS OF IPS MANNSFELDI (WACHTL, 1879) (CURCULIONIDAE: SCOLYTINAE) IN TURKEY
}

\author{
SARIKAYA, O. $.^{*}-$ KARACEYLAN, I. B. ${ }^{2}-$ SEN, I. ${ }^{3}$ \\ ${ }^{I}$ Suleyman Demirel University, Faculty of Forestry \\ Isparta, Turkey \\ ${ }^{2}$ Suleyman Demirel University, Faculty of Science and Arts, Department of Biology \\ Isparta, Turkey \\ ${ }^{3}$ Suleyman Demirel University, Faculty of Technology, Department of Biomedical Engineering \\ Isparta, Turkey \\ *Corresponding author \\ e-mail: oguzhansarikaya@sdu.edu.tr; phone:+90-246-211 3964; fax:+90-246-211 3948 \\ (Received $31^{\text {st }}$ Jan 2018; Accepted $26^{\text {th }}$ Apr 2018)
}

\begin{abstract}
Climate change has reached the highest rates of the last 1.400 years. This has begun to attract the attention of researchers, and the number of studies on estimation of the environmental impacts of climate change on species has also begun to increase. Ips mannsfeldi (Wachtl, 1879) is a bark beetle (Curculionidae: Scolytinae) species spreading on black pine (Pinus nigra) fields in Turkey. This study aims to model the current and future (2070) distribution of the species according to two different global climate change scenarios. Locations of I. mannsfeldi specimens that were collected in different stands were recorded with GPS. Current and future potential distribution areas of the species have been determined using maximum entropy modeling. RCP4.5 and RCP8.5 emission scenarios reported in IPCC5 were used to estimate the future potential distribution of the species. As a result of the study, it is determined that the species distributes on the Black pine (Pinus nigra) forests throughout the Mediterranean part of Turkey at the present time. According to projections to 2070 the distribution area will expand towards the Aegean region. Depending on the changing climatic conditions, it can be seen that this species expands its distribution area and may be a potential pest that causes economic damage to black pine fields in the coming period.
\end{abstract}

Keywords: Ips mannsfeldi, MaxEnt, Pinus nigra, climate change, future prediction, modeling

\section{Introduction}

The last three decades have been successively warmer periods of the last 1.400 years in the Northern Hemisphere. Evidence regarding impacts of observed climate change is the strongest and most comprehensive for natural systems. In addition to these impacts, many terrestrial, freshwater and marine species have to shift their geographic ranges, seasonal activities, migration patterns, abundances and species interactions in response to ongoing climate change (IPCC, 2014). Especially, insect communities may severely be impacted by increasing temperature which will affect almost all life history parameters, such as emergence, growth rate, and voltinism (Bale et al., 2002; Cornelissen, 2011). One of the important insect assemblages suffering from climate change is inhabitants of the forest ecosystems because plants and their associated phytophagous insects comprise a major proportion of terrestrial biodiversity (Strong et al., 1984; Wilson, 1988; Chapman, 2009). So, understanding the potential impacts of climate change on insects, especially forest dependent species, is essential for 
management strategies (Met Office, 2011). In this context, bark beetles are among the most serious forest pests world-wide (Epanchin-Niell et al., 2014). One of these beetles is Ips mannsfeldi (Wachtl, 1879) which distributes only in black pine and scots pine forests of Austria, Corsica, Romania, Croatia, Bosnia Herzegovina, Macedonia and Turkey (Pfeffer, 1995; Stauffer et al., 1997; Selmi, 1998). The distribution of $I$. mannsfeldi is congruent with the natural range of its host trees (Pfeffer, 1995).

Species distribution models estimate the distribution of species by examining the relationships between the occurrence records of species and the environmental characteristics of the occurrence sites (Elith, 2011). MaxEnt is a software for species distribution modeling which estimates the distribution of species using presence-only records and maximum entropy algorithm (Phillips, 2017).

The aims of the study were to model the current and future (2070) distributions of Ips mannsfeldi in Turkey according to RCP4.5 and RCP8.5 (Representational Concentration Pathways) climate change scenarios reported in The Fifth Assessment Report of the Intergovernmental Panel on Climate Change (IPCC5).

\section{Materials and Methods}

\section{Occurrence Data}

Specimens were collected from trees weakened by other insects or drought, trunks in forest stands and trap woods that were placed by Forestry Administration. Specimens were collected coincidentally during field works (Figure 1).

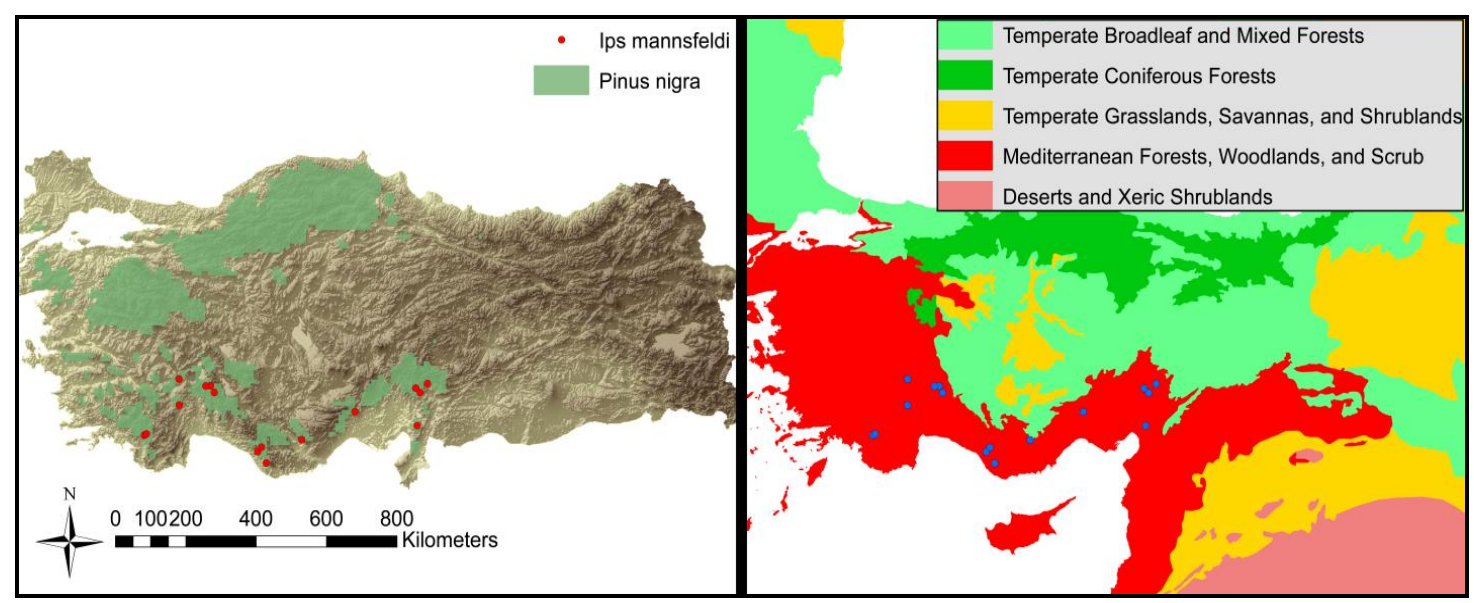

Figure 1. Distribution of the host tree Pinus nigra in Turkey and the occurrence localities (left). Biome map of Turkey (right)

The study extent was limited to the part of the Mediterranean biome in Turkey (Olson, 2001) where the host tree Pinus nigra is distributed and 10.000 background points also called the "pseudo-absences" (Merow et al., 2013) were selected from this area (Figure 1). This approach is ideal as limiting the study extent to areas that are accessible to the species being studied improves the model performance and prevents over-inflation of evaluation metrics (Barve et al., 2011; Soberon and Peterson, 2005; Jimenez-Valverde et al., 2008). 


\section{Environmental Data}

SRTM30 digital elevation model (Farr and Kobrick, 2000) and 19 Bioclim variables of the WorldClim database (Hijmans et al., 2005) were used as the environmental variables. Variables showing strong correlation were identified using Spearman's rank correlation coefficient ( $\mathrm{rs}>0.7$ ). Among the correlated variables the ones that are expected to contribute to the distribution of the species were selected. Five environmental variables were used in the final model (Table 1). Bioclim variables for 2070 (CCSM4) and two greenhouse gas emission scenarios RCP4.5 and RCP8.5 were used to project the model. All variable rasters were at 30 arc-seconds resolution.

Table 1. Environmental variables used in the study

\begin{tabular}{c|c}
\hline Variable & Description \\
\hline Elevation* & - \\
WC1 & Annual Mean Temperature \\
WC2 & Mean Diurnal Range (Mean of monthly (max temp - min temp)) \\
WC3* & Isothermality (WC2/WC7) $(* 100)$ \\
WC4 & Temperature Seasonality (standard deviation *100) \\
WC5 & Max Temperature of Warmest Month \\
WC6 & Min Temperature of Coldest Month \\
WC7* & Temperature Annual Range (WC5-WC6) \\
WC8 & Mean Temperature of Wettest Quarter \\
WC9 & Mean Temperature of Driest Quarter \\
WC10 & Mean Temperature of Warmest Quarter \\
WC11 & Mean Temperature of Coldest Quarter \\
WC12 & Annual Precipitation \\
WC13* & Precipitation of Wettest Month \\
WC14* & Precipitation of Driest Month \\
WC15 & Precipitation of Wettest Quarter \\
WC16 & Precipitation of Driest Quarter \\
WC17 & Precipitation of Warmest Quarter \\
WC18 & Precipitation of Coldest Quarter \\
WC19 & Precipitation Seasonality (Coefficient of Variation) \\
\hline
\end{tabular}

* indicates the variables used in the final model

\section{Distribution Modeling}

MaxEnt version 3.4.1 (Phillips et al., 2006; Phillips et al., 2017) was used through the R package "dismo" (Hijmans et al., 2017) to model the distribution of the species. The model was fine-tuned using the R package "ENMeval" (Muscarella et al., 2014) with trying all combinations of feature types and regularization multiplier values $0.5,1$ 10. Since the sample size is low $(n=11) \mathrm{k}-1$ jackknife method described in Pearson et al. (2007) was used to validate the model. Akaike Information Criterion corrected for small samples sizes (AICc) was used as the model selection criterion (Warren et al., 2011). Final binary distribution maps were generated using the threshold value which maximized sensitivity (true positive rate) plus specificity (true negative rate) since this value also maximizes the True Skill Statistic and is not affected by pseudo-absences and prevalence (Liu et al., 2005; Allouche, 2006). Multivariate environmental surface similarity (MESS) plots (Elith et al., 2010) were created using the R package "Ecospat" (Broennimann et al., 2016). Finally, the limiting factor surface map (Elith et al., 2010) was calculated using the R package "rmaxent" (Baumgartner et al., 2017). 


\section{Results}

The final model was selected based on the fine tuning using the AICc value and the best model only used Linear and Quadrat features with a regularization multiplier value of 0.5 (Figure 2). The ROC curve of the final model shows a high predictive power with an AUC score of 0.88 (Figure 3).

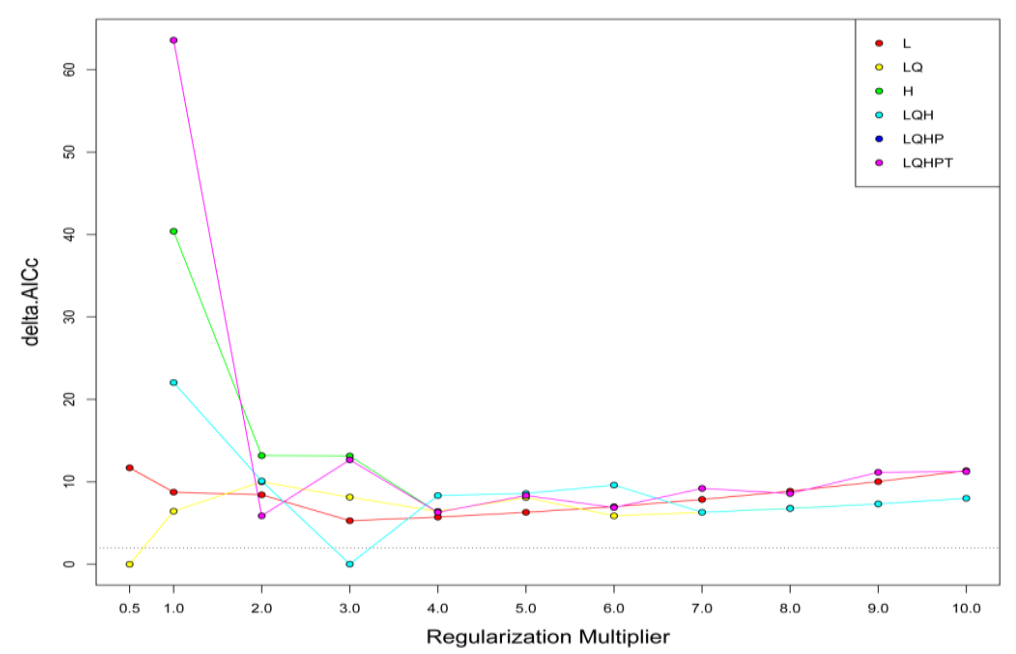

Figure 2. Results of the fine tuning. X axis corresponds to the beta regularization value of that model. Y axis corresponds to the difference between the smallest AICc value and the AICc value of that model. Legend shows six different combinations of the feature types

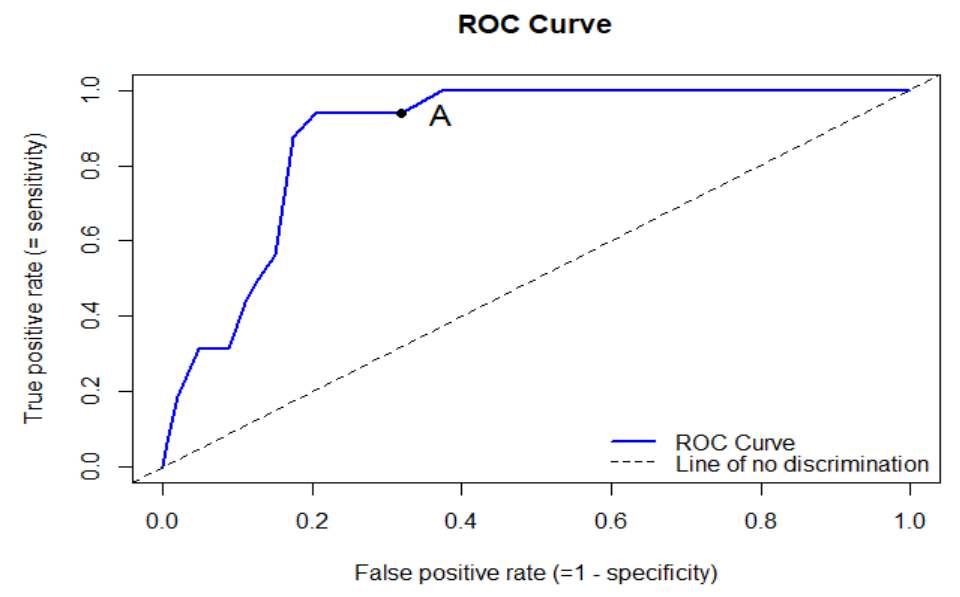

Figure 3. The Receiver Operating Characteristic curve of the final model. The AUC score is the area under this curve and the AUC score of this model is 0.88. The AUC score of the line of no discrimination is 0.5 which means no predictive power. The point $A$ corresponds to the threshold value of 0.58 used in producing the binary maps

The most important variable for the model was elevation (Figure 4). It appears to have the most useful information as well as more unique information then other variables. 


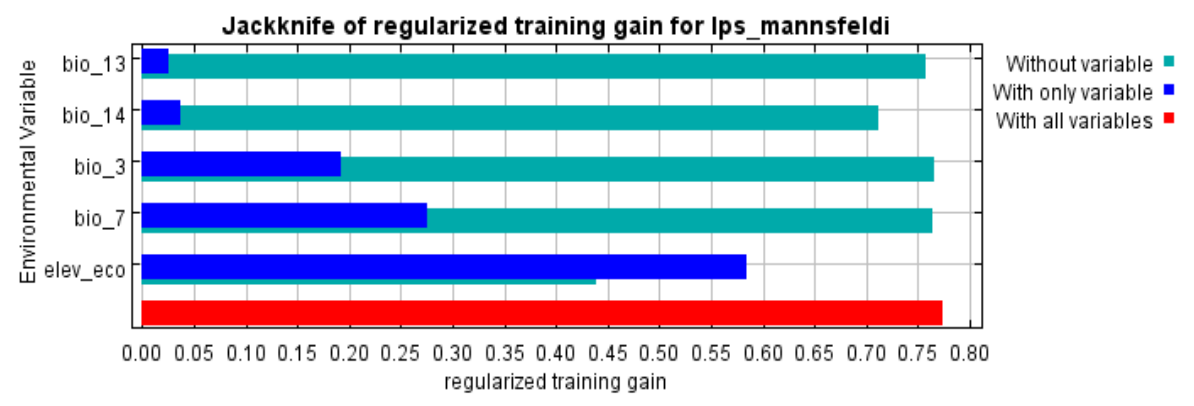

Figure 4. Results of jackknife test of variable importance (Light blue: without variable, Blue: with only variable, Red: with all variables)

The threshold value that maximized the sum of true positive rate and true negative rate was 0.58 (Figure 3). This value was used to generate the binary maps of current and future distributions (Figure 5). Projections predict an expansion of the distribution area towards north-western part of Turkey in both climate change scenarios.

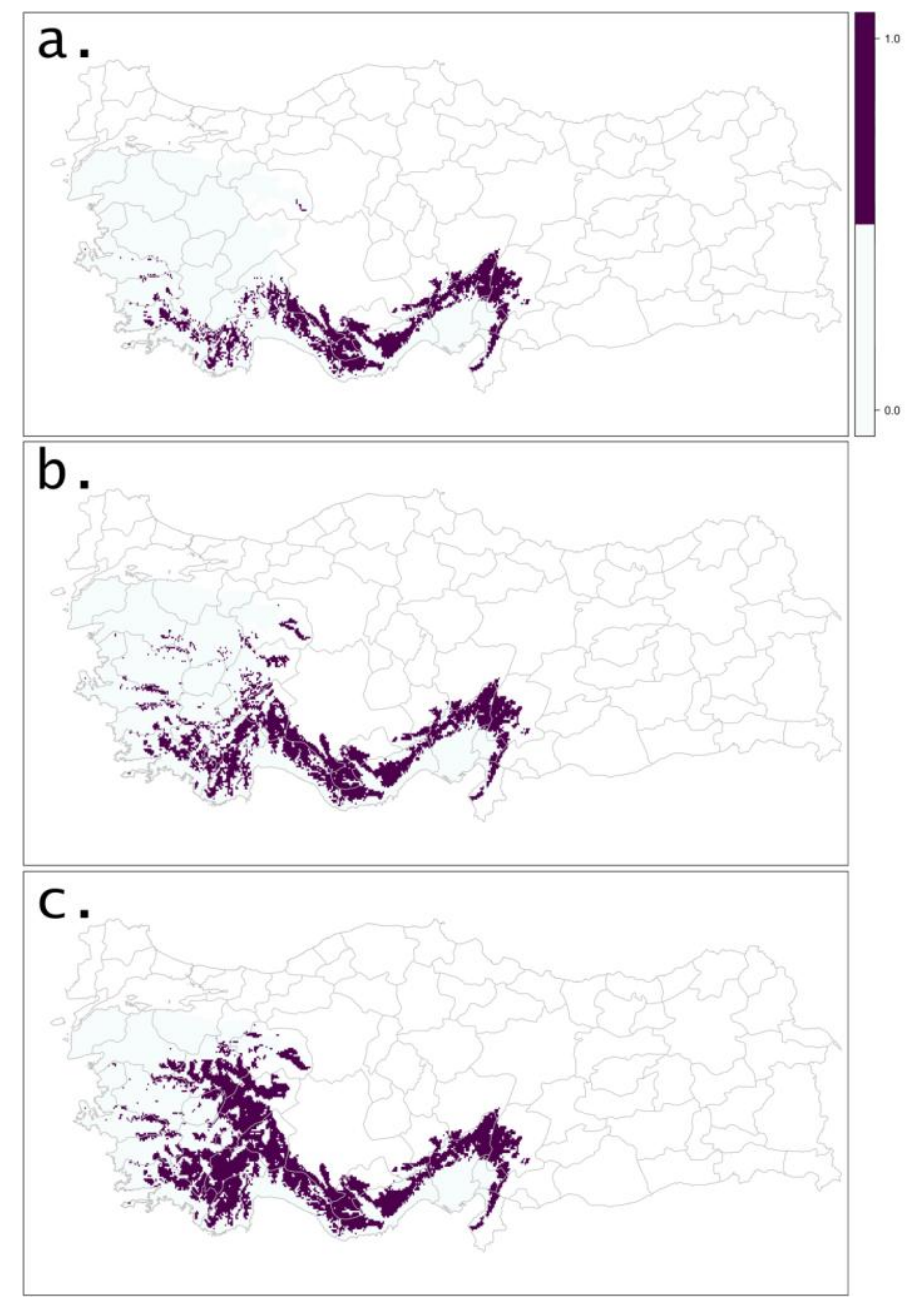

Figure 5. Distribution maps of Ips mannsfeldi according to the model (a: current distribution, b: Distribution in 2070 according to RCP4.5 climate change scenario, c: Distribution in 2070 according to RCP8.5 scenario) 
MESS plots show how much the model has to extrapolate in a given region (Figure 6). While the areas with negative values are extrapolated into, the areas with positive values require no extrapolation.

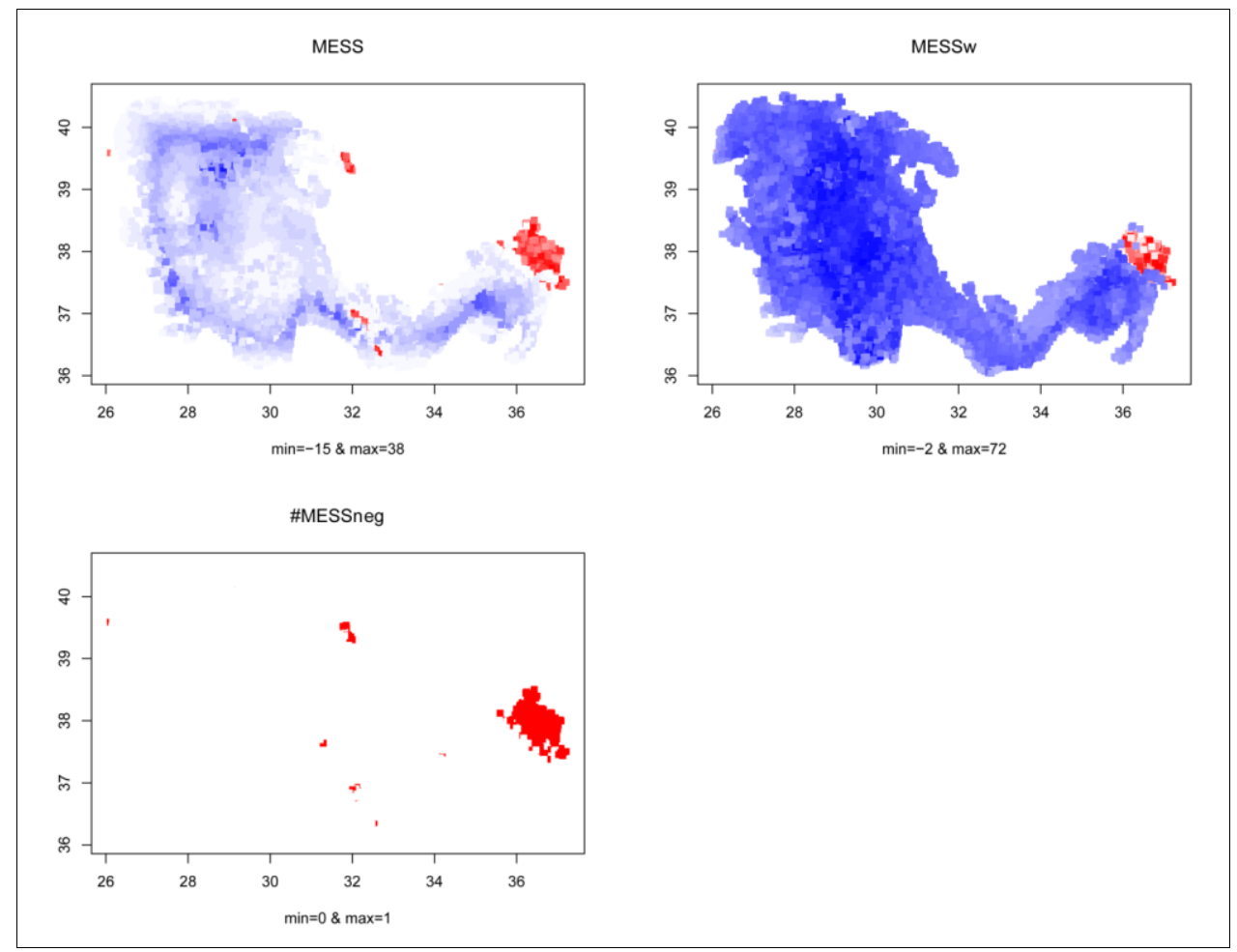

Figure 6. MESS plots of the model projection to 2070 according to RCP8.5. Pixels in red indicate sites of extrapolation. MESSw plot is the MESS plot weighted by the number of extrapolating predictors. MESSneg plot shows how many predictors are extrapolating in each site

Predictions into negative MESS areas should be approached carefully. Limiting factors map is shown in Figure 7.

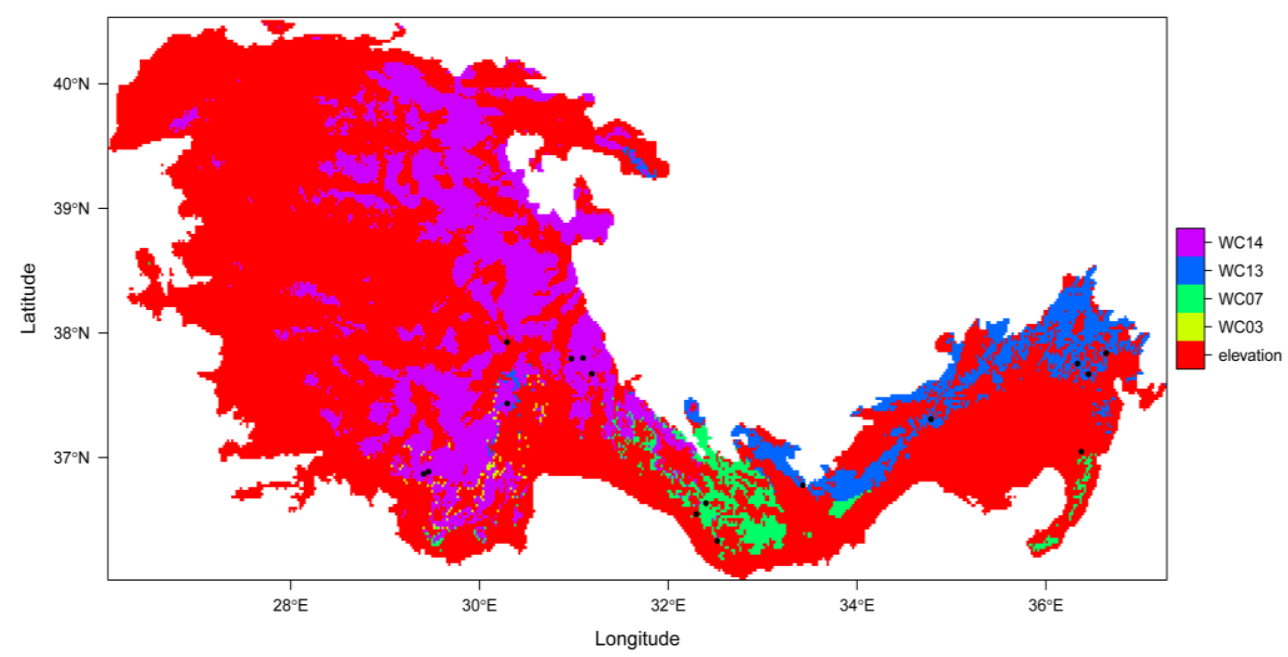

Figure 7. Limiting factors map. This map indicates the most limiting factor in each grid cell 


\section{Discussion}

Our results show that Ips mannsfeldi will expand its range towards north-western part of Turkey (Figure 5). The most important factor for the distribution of the species is elevation. However, it's important to note that elevation showed strong correlation with most of the bioclim variables regarding temperature in our case. We chose to keep elevation as a predictor because of its relevance to the distribution of the host tree Pinus nigra which occurs between 1000-1800m along the Taurus Mountains in the Mediterranean region and in the inner Anatolian region (Atalay and Efe, 2012). Elevation is also the most limiting factor for the distribution of the species (Figure 7). Another curious result is that the second most limiting factor which also prevents the distribution towards north-west part of Turkey is the precipitation of the driest month (WC14). A map of $\triangle \mathrm{WC14}$ shows that according to RCP8.5 climate change scenario precipitation of the driest month will drop in those regions (Figure 8). Precipitation is known to be important in the distribution of other Scolytinae species. For example, in their work Mendoza et al. (2011) found that Dendroctonus rhizophagus had a narrow ecological niche in terms of precipitation. Furthermore, in their ecological niche factor analysis with 19 bioclim variables the species was "essentially linked to the precipitation of the driest month". According to our model the decrease in this variable will make the Aegean region (north-western area of Turkey) available to the species by 2070 .

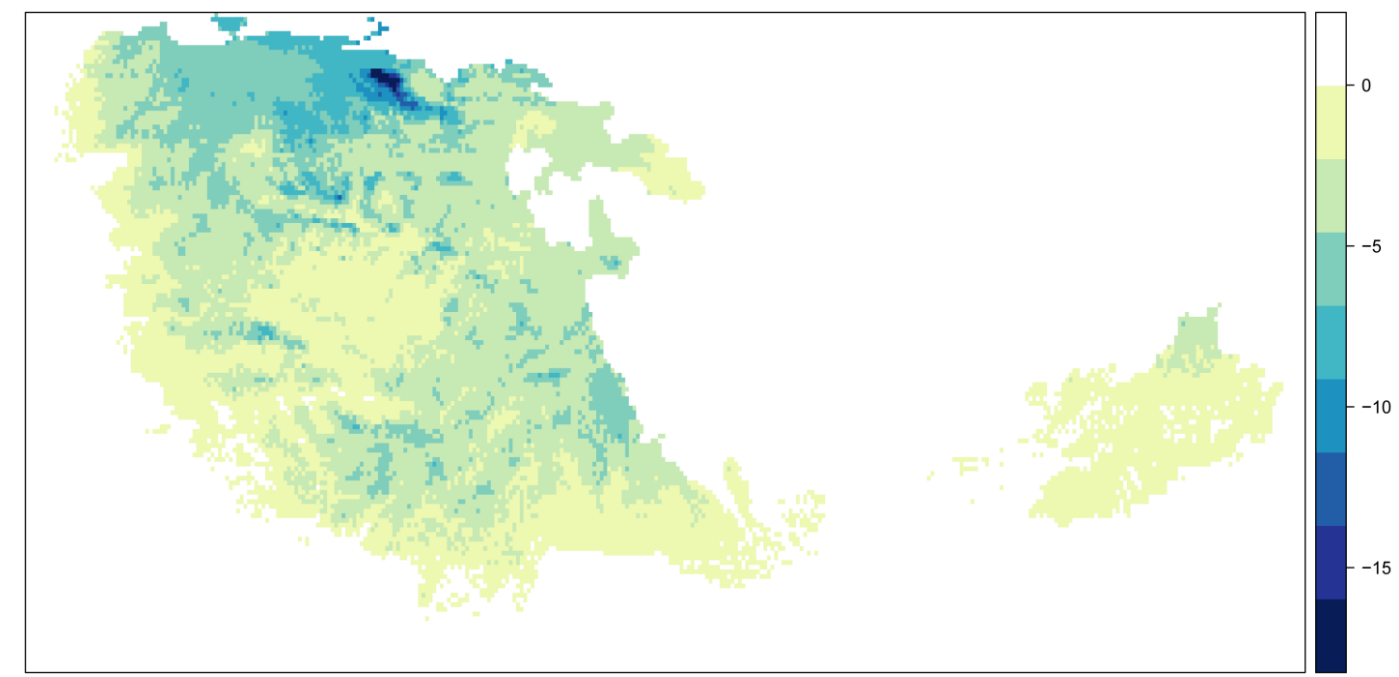

Figure 8. The map showing the difference between the precipitation of the driest month value (WC14) of current and 2070 RCP8.5 data of each grid cell

\section{Conclusion}

In light of this data, the species has the potential to be an important pest species in the future. The data on the biology and the distribution of Ips mannsfeldi is very limited at the moment. Further studies are needed to explore the specific geographical distribution of Ips mannsfeldi which depends on forest characteristics across its potential distribution area. 
Acknowledgements. This study was a part of TUBITAK-1002 project. We express our sincere appreciation to The Scientific and Technological Research Council of Turkey (TUBITAK) for their financial support by project which numbered as 1130198 .

\section{REFERENCES}

[1] Allouche, O., Tsoar, A., Kadmon, R. (2006): Assessing the accuracy of species distribution models: prevalence, kappa and the true skill statistic (TSS). - Journal of Applied Ecology 43: 1223-1232.

[2] Atalay, İ., Efe, R. (2012): Ecological attributes and distribution of Anatolian black pine [Pinus nigra Arnold. subsp. pallasiana Lamb.Holmboe] in Turkey. - Journal of Environmental Biology 33: 509-519.

[3] Bale J. S., Masters, G. J., Hodkinson, I. D., Awmack, C., Bezemer, T. M. (2002): Herbivory in global climate change research: direct effects of rising temperature on insect herbivores. - Global Change Biology 8: 1-16.

[4] Barve, N., Barve, V., Jiménez-Valverde, A., Lira-Noriega, A., Maher, S. P., Peterson, A. T., Villalobos, F. (2011): The crucial role of the accessible area in ecological niche modeling and species distribution modeling. - Ecological Modelling 222: 1810-1819.

[5] Baumgartner, J., Wilson, P., Esperon-Rodriguez, M. (2017): rmaxent: Tools for working with Maxent in $\mathrm{R}_{-} . \mathrm{R}$ package version 0.4.9.9000, <URL: https://github.com/johnbaums/rmaxent>.

[6] Chapman, A. D. (2009): Numbers of Living Species in Australia and the World. Canberra: - Australian Biological Resource Study: 1-84.

[7] Cornelissen, T. (2011): Climate change and its effects on terrestrial insects and herbivory patterns. - Neotropical Entomology 40: 155-163.

[8] Elith, J., Kearney, M., Phillips, S. (2010): The art of modelling range-shifting species. Methods in Ecology and Evolution 1: 330-342.

[9] Elith, J., Phillips, S. J., Hastie, T., Dudík, M., Chee, Y. E., Yates, C. J. (2011): A statistical explanation of MaxEnt for ecologists. - Diversity and distributions 17(1): 4357.

[10] Epanchin-Niell, R. S., Brockerhoff, E. G., Kean, J. M., Turner, J. A. (2014): Designing cost-efficient surveillance for early detection and control of multiple biological invaders. - Ecological Applications 24: 1258-1274.

[11] Farr, T. G., Kobrick, M. (2000): Shuttle Radar Topography Mission produces a wealth of data, Amer. Geophys. - Union Eos 81: 583-585.

[12] Pearson, R. G., Raxworthy, C. J., Nakamura, M., Peterson, A. T. (2007): Predicting species distributions from small numbers of occurrence records: a test case using cryptic geckos in Madagascar. - Journal of Biogeography 34: 102-117.

[13] Hijmans, R. J., Cameron, S. E., Parra, J. L., Jones, P. G., Jarvis, A. (2005): Very high resolution interpolated climate surfaces for global land areas. - International Journal of Climatology 25: 1965-1978.

[14] IPCC (2014): Climate Change 2014: Synthesis Report. Contribution of Working Groups I, II and III to the Fifth Assessment Report of the Intergovernmental Panel on Climate Change [Core Writing Team, R. K. Pachauri and L. A. Meyer (eds.)]. - IPCC, Geneva, Switzerland, $151 \mathrm{pp}$.

[15] Jimenez-Valverde, A., Lobo, M., Hortal, J. (2008): Not as good as they seem: The importance of concepts in species distribution modelling. - Diversity \& Distributions 14 : 885-890.

[16] Liu, C., Berry, P. M., Dawson, T. P., Pearson, R. G. (2005): Selecting thresholds of occurrence in the prediction of species distributions. - Ecography 28: 385-393. 
[17] Merow, C., Smith, M. J., Silander, J. A. (2013): A practical guide to MaxEnt for modeling species' distributions: What it does, and why inputs and settings matter. Ecography 36: 1058-1069.

[18] Mendoza, M. G., Salinas-Moreno, Y., Olivo-Martinez, A., Zuniga, G. (2011): Factors Influencing the Geographical Distribution of Dendroctonus rhizophagus (Coleoptera: Curculionidae: Scolytinae) in the Sierra Madre Occidental, Mexico. - Environmental Entomology 40: 549-559.

[19] Met Office (2011): Climate: observations, projections and impacts. - Turkey. 124 pp.

[20] Muscarella, R., Galante, P. J., Soley-Guardia, M., Boria, R. A., Kass, J., Uriarte, M., Anderson, R. P. (2014): ENMeval: An R package for conducting spatially independent evaluations and estimating optimal model complexity for ecological niche models. Methods in Ecology and Evolution 5(11):1198-1205.

[21] Broennimann, O., Di Cola, V., Guisan, A. (2016): Ecospat: Spatial Ecology Miscellaneous Methods. $\mathrm{R}$ package version 2.1.1. https://CRAN.Rproject.org/package =ecospat

[22] Olson, D. M., Dinerstein, E., Wikramanayake, E. D., Burgess, N. D., Powell, G. V. N., Underwood, E. C., D'Amico, J. A., Itoua, I., Strand, H. E., Morrison, J. C., Loucks, C. J., Allnutt, T. F., Ricketts, T. H., Kura, Y., Lamoreux, J. F., Wettengel, W. W., Hedao, P., Kassem, K. R. (2001): Terrestrial ecoregions of the world: a new map of life on Earth. Bioscience 51: 933-938.

[23] Pfeffer A. (1995): Zentral und westpaläarktische Borken und Kernkäfer. Naturhistorisches Museum Basel, 310 p.

[24] Phillips, S. J., Anderson, R. P., Schapire, R. E. (2006): Maximum entropy modeling of species geographic distributions. - Ecological Modelling 190: 231-259.

[25] Phillips, S. J., Anderson, R. P., Dudík, M., Schapire, R. E., Blair, M. E. (2017): Opening the black box: An open-source release of Maxent. - Ecography 40: 887-893.

[26] Hijmans, R. J., Phillips, S., Leathwick, J., Elith, J. (2017): Dismo: Species Distribution Modeling. R package version 1.1-4. https://CRAN.R-project.org/package=dismo

[27] Selmi, E. (1998): Türkiye Kabuk Böcekleri ve Savaşı. - İ.Ü. Yayın No: 4042, Fen Bilimleri Enstitüsü Yayın No: 11, 196 p.

[28] Soberon, J., Peterson, A. T. (2005): Interpretation of models of fundamental ecological niches and species' distributional areas. - Biodiversity Informatics 2: 1-10.

[29] Stauffer, C., Lakatos, F., Hewitt, G. M. (1997): The phylogenetic relationships of seven European Ips (Scolytidae, Ipinae) species. - Insect Molecular Biology 6: 233-240.

[30] Strong, D. R., Lawton, J. H., Southwood, T. R. E. (1984): Insects on Plants. Community Patterns and Mechanisms. - Oxford: Blackwell Scientific.

[31] Warren, D. L., Siefert, S. N. (2011): Ecological niche modeling in Maxent: The importance of model complexity and the performance of model selection criteria. Ecological Applications 21: 335-342.

[32] Wilson, E. O. (1988): Biodiversity. - Washington: National Academy Press. 